\title{
Teoria CRItica Decolonial sobre UM VAZio EPISTEMOLÓGICO NA ACADEMIA BRASILEIRA
}

João José Veras de Souza ${ }^{1}$

RESUMO: Com o presente artigo objetiva-se introduzir, de forma muito breve, a teoria critica decolonial, seus juizos em torno da ideia de modernidade e as epistemologias dela decorrentes que têm sido difundidas, especialmente, por meio das ciências sociais e humanas, na América Latina. Com isso, procura-se chamar a atenção sobre um "vazio epistemológico" na academia brasileira que consiste na ausência de difusão dos chamados estudos pós-coloniais, enquanto possibilidade de acesso a outro paradigma de conhecimento, frente ao domínio, quase absoluto, da teoria social advinda da Europa e dos Estados Unidos. Para tanto, insere-se para o debate um caso empírico paradigmático desse vazio na academia brasileira: o conteúdo bibliográfico da disciplina Teorias da Sociedade, da Política e da Natureza - do currículo do Programa de Pós Graduação Interdisciplinar em Ciências Humanas, da Universidade Federal de Santa Catarina-UFSC.

PALAVRAS-CHAVE: Teoria critica decolonial. Modernidade. Colonialidade. Academia brasileira.

A ausência de reflexões sobre a geopolítica e a espacialidade na produção de conhecimento vai a par com a falta de reflexão crítica quanto ao empenhamento da filosofia e dos filósofos ocidentais com a Europa enquanto local epistémico privilegiado (MALDONADO-TORRES, 2008).

\section{$O$ caso de uma disciplina acadêmica}

O presente artigo, partindo da constatação de que a academia brasileira pouca se esforça para sair do circulo fechado dos saberes eurocênctricos - objetiva apresentar, de forma breve e introdutória, a teoria critica decolonial, bem como, parcialmente, suas análises e questionamentos em torno da ideia de modernidade e algumas epistemologias por esta produzida e difundida, especialmente por meio das ciências sociais e humanas, na América Latina, desde a fase de sua conquista a partir de 1492. A pretensão específica aqui é

1 Doutorando do Programa de Pós-Graduação Interdisciplinar em Ciências Humanas, Universidade Federal de Santa Catarina. 
chamar atenção sobre um "vazio epistemológico" na academia brasileira - ensino superior - sobre tais estudos, a exemplo do que ocorre no programa da disciplina: Teorias da Sociedade, da Política e da Natureza - do currículo do Programa de Pós Graduação Interdisciplinar em Ciências Humanas, da Universidade Federal de Santa Catarina-UFSC - apesar do rico, extenso e profundo conteúdo nele proposto.

Estruturalmente, após discorrer sobre o caso da disciplina referida, o artigo parte da apresentação do que se titula aqui como outro paradigma epistemológico de saber (uma das ausências reclamadas) a Teoria Critica Decolonial; seguindo para o enfrentamento de três temas que lhes são fundamentais: modernidade, eurocentrismo e matriz colonial de poder, a partir das posições, de um lado, de Imannuel Kant, Georg W. F. Hegel, Jügens Habermas, Martin Heidegger e Emmanuel Lévinas com, de outro lado, contrapontos de Enrique Dussel, Walter Mignolo, Nelson Madonaldo-Torres, Anibal Quijano, entre outros; para, no final, fechar com a perspectiva que a teoria apresenta como saída - frente à condição imposta pela modernidade..

Vejamos, de inicio, os objetivos da referida disciplina acadêmica, conforme sua ementa:

Disciplina destinada à discussão de autores clássicos e contemporâneos cujas reflexões teóricas deram uma contribuição importante para pensar a sociedade e a política, assim como as relações destas com a natureza. Cada programa deverá selecionar, para maior aprofundamento, alguns pensadores e/ou correntes que sejam expressivos da diversidade de posições teóricas existentes atualmente, apontando especialmente a decifrar a genealogia das mesmas (Ementa da disciplina inscrita sob o código ICH4002000, site do programa: http://ppgd.ufsc.br/)

Muito embora a disciplina se destine a trabalhar com autores clássicos e contemporâneos, cujas reflexões teóricas deram contribuições importantes para se pensar a sociedade, a politica e a natureza, sua bibliografia não traz, para ficar no nosso continente, autores latino-americanos, ressalvadas raríssimas exceções. Deste angulo, autores externos ao eixo Europa-EUA são invisibilizados ou considerados inexpressivos no bojo dessa produção de saber meritório. A 
diversidade de posições teóricas que se busca no programa está centrada naquela corrente entre os autores europeus e norte-americanos e não entre estes e outros fora deste circulo geo-cultural eurocêntrico.

Quanto ao aspecto temático, temos que, conforme o Programa da Disciplina, dos 15 (quinze) temas das aulas do semestre, pelo menos 8 (oito) tratam diretamente da ideia de modernidade como conceito já, de antemão, estabelecido pelos pensadores europeus. No tema "Será que somos modernos" (aula 7), das vinte referências bibliográficas indicadas para estudos - em sua maioria formada pelos cânones do pensameno universalista européu como Habermas, Nietzsche, Noberto Elias, Giddens, Bauman, Horkheimer, Adorno, Latour e Lyotard - apenas uma referência não era de autor europeu. O que reserva a possibilidade dali sair, tão-só, uma "critica eurocêntrica da modernidade", jamais fora desse paradigma geo-epistemológico. E o curso todo segue nessa linha.

Ainda quanto ao conteúdo, significativas são as temáticas trazidas pelo programa com as quais trabalham aqueles autores: A teoria social e politica (aula 2), centrada na concepção européia de teoria social e politica indiferente à produção de autores latinos, africanos e asiáticos; a análise das categorias antigo e moderno (aula 3), aqui o oposto de moderno apresentado é antigo, apontando uma concepção linear de história e de produção de conhecimento; a ideia de igualdade (aula 4) e de liberdade (aula 5) apresentadas como umas das maiores invenções da modernidade, estraídas logicamente das revoluções burguesas daquele continente e também do norte-americano - o dilema revolucionários x conservadores (aula 6); a ideia de modernidade (aula 7); a natureza da modernidade (aula 8); modernidade e técnica (aula 9); modernidade e ética (aula 10); revisitando a condição humana (aula 11), o humano europeu apresentado como universalista, portanto modelo ontológico válido para todos, naturalmente; revisitando a natureza humana (aula 12), humano, repete-se, naturalmente o europeu; o homem e o animal (aula 13) e modernidade e religião. Secularização, teologia e profanação (aula 14), aqui muito embora se fale sobre a religião, todavia nenhum referência, por exemplo, à teologia da libertação, que é uma criação latino americana... tudo a partir dos parâmetros teóricos do pensamento europeu por seus pensadores. 
A ideia de modernidade está presente, explicita e implicitamente, em quase todos os tópicos do programa, como se a mesma fosse auto -referente e fizesse parte, naturalmente, da realidade latino-americana, que fosse familiar e se integrasse ao cabedal dos problemas regionais e locais da América Latina, exatamente no sentido colocado pelos pensadores europeus.

Tal "vazio" - que se expressa como uma indiferença epistemológica gritante - impede, no espaço acadêmico, a difusão e o debate de um outro tipo de saber e reflexão a respeito da sociedade, da política e da natureza. Uma outra maneira de perceber com distinto tipo de saber e compreensão do mundo que não esteja necessariamente vinculado, de forma exclusiva, ao pensamento produzido histórica e geograficamente pelos pensadores europeus e norte-americanos, os quais têm formado, secularmente, gerações de cientistas, também nas áreas humanas, das universidades latino-americanas. Referida postura acadêmica produz outras consequências como a de passar a ideia, para os acadêmicos, de que não existe produção intelectual fora do eixo Europa/Estados Unidos da América do Norte (e se existe não merece atenção), o que vale dizer: não há possibilidade de produção de conhecimento local a partir dos locais, o que resulta na condenação desdes à eterna reprodução dos saberes exógenos.

A propósito, diante do resultado de uma pesquisa realizada pelo Jornal Folha de São Paulo, entre intelecutais brasileiro, na qual, dos cem livros de não ficção mais influentes nos últimos 500 anos, apenas um brasileiro - Euclides da Cunha - fora indicado, Milton Santos (SANTOS, 1999), faz as seguintes reflexões, especialmente quanto à manufatura da falsa ideia de universalidade (a que todos devem seguir) a qual posturas acadêmicas, como a que acabamos de apontar, reforçam:

As consequências dessa visão distorcida do mundo são, na realidade, devastadoras para as ciências humanas, na medida em que adotem pontos de partida redutores e, neutralizando o ímpeto da crítica e aceitando raciocínios estabelecidos em função de outras realidades, conduzam a fornecer exegeses e exemplos resignados. Quando o parâmetro é a universalidade, as ideias começam e terminam com um pensamento filosófico, que pode ser procurado e encontrado, não importa onde estejamos. Tal atitude tem reflexos sobre a conformação do 
gosto e das escolhas, conduzindo, de forma talvez imperceptível, a reproduzir, com exemplos novos, formulações alheias, aceitas como se fossem universais. Os mencionados desvios são limitadores na elaboração dos pensamentos brasileiro e latino-americano e em nossa própria visão de nós mesmos e do continente. É como se todos quiséssemos ser europeus e agora um pouco mais, porque também queremos ser norte-americanos. Até mesmo a elegância no dizer é copiada. Não se trata de dar as costas à realidade do mundo, mas de pensá-la a partir do que somos, enriquecendo-a universalmente com as nossas ideias; e aceitando ser, desse modo, submetidos a uma crítica universalista e não propriamente européia ou norte-americana (SANTOS, 1999).

Também criticando essa condição, a cientista social australiana Raewin Connell, propõe uma definição ordodoxa para teoria: “Teoria é o trabalho que o centro faz" (CONNELL, 2012, p. 11). Para a autora, concordando Paulin Hountond-ji, de fato, há uma divisão social da produção do conhecimento que tem caráter geopolitico, pela qual, numa ponta está o mundo colonizado - a periferia, em que se coleta dados - e na outra o mundo civilizado (o centro) que produz a teoria. Para ela, as instituições de ensino da periferia estão estruturadas para receber instruções das metrópoles, instruções estas que reificam a experiência social do Norte excluindo a condição colonial do Sul como um processo social determinante. Ainda de acordo com Connell:

As formas materiais dessa dependência são familiares. Intelectuais da periferia viajam para a metrópole para obter treinamento avançado. Nós buscamos publicar nos jornais da metrópole, juntar-nos aos "invisible colleges" de lá, e, se tivermos sorte, obter empregos nas suas instituições. Essas práticas agora são poderosamente reforçadas pela governança neoliberal das universidades, preocupada com a posição competitiva dos rankings internacionais que são - surpresa! - centrados no Norte global e utilizam o critério de excelência lá desenvolvido (CONNELL, 2012, p. 11).

O que se quer aqui problematiza é essa histórica impossibilidade da visibilidade a outro conhecimento critico no ensino superior brasileiro, mormente saberes locais - que se difunde para outras instituições educacionais de reprodução e de conhecimento formal - e de se promover o acesso e o diálo- 
go de saberes paradigmáticos, para além do acesso e o diálogo de saberes programáticos intra-eurocêntricos que se vê nas academias (caso modelar da disciplina em questão), sobretudo considerando que, no exemplo que trazemos a baila, estamos tratando de uma disciplina constante de um curso de doutorado em ciências humanas, de caráter interdisciplinar. ${ }^{2}$ Nesse sentido, “...de nada sirve incorporar la transdisciplinaridad y el pensamento complexo, se ello não contribuye a permitir un intercambio cognitivo entre la ciencia occidental y formas post-occidentales de producción de conociminentos" (CASTRO-GOMES, 2007).

Pelo prisma de seu conteúdo, tenho que a disciplina em questão, por sua bibliografia, parte (para ficar numa categoria), de uma concepção de modernidade já tão naturalizada pelos cânones do conhecimento eurocêntrico, de modo que questionamentos e confrontações teóricas a seu respeito só podem ser possíveis desde dentro de seus limites conceituais e, assim, com suas categorias e cosmologia de ideias, tendo como parâmetro fundamentalmente uma "perspectiva intra-moderna".

$\mathrm{Na}$ sequência será exposta, de forma breve, linhas do pensamento de alguns pesquisadores das ciências humanas, cujas naturezas de visões diferem substancialmente das sínteses de saberes que a bibliografia em questão oportuniza analisar ao longo das leituras/debates em sala de aula. Serão curtos apontamentos com os quais se procurará dar a dimensão da importância do problema, algumas questões de fundo as quais têm sido caras para um suporte intelectual, desde a América Latina, que não se limite à reprodução dos conhecimentos postos pelos aclamados centros de saberes. É uma exposição em que a diversidade de visões não são descuradas e, no caso, o que se apresenta manufaturando o "vazio epistemológico" aqui reclamado é toda uma tradição histórica de conhecimento eurocêntrico - tão comum nos currículos dos sistemas de educação superior nos países considerados periferias (da América Latina, por exemplo) - pela qual temos sido formados ao longo de séculos.

2 O presente artigo se presta a contribuir, propositivamente, com a disciplina em questão afim de que a mesma possa, no contexto dos estudos interdiciplinares, alargar o seu rol epistemológico, sobretudo voltando-se a outros paradigmas de conhecimento, problematizações e esquemas interpretativos outros da realidade latino-americana. 


\section{A teoria critica decolonial}

Desde a década de 90, do século passado, um grupo de pesquisadores das ciências humanas, em sua maioria latino-americanos, tem se dedicado, de maneira orgânica, através de encontros e produção de obras coletivas e individuais, a pensar a geopolitica, especialmente o papel da América Latina em relação à Europa e EUA, tendo como parâmetro o conhecimento e o poder no contexto da modernidade. O grupo passou a ser conhecido sob a denominação de Programa de Pesquisa de Modernidade/Colonialidade-MC (ESCOBAR, 2003). ${ }^{3}$

O conjunto da produção cientifica do Programa MC ganhou o nome, para alguns, de teoria critica decolonial e, para outros, de teoria social latino-americana, entre outras denominações no estilo. Independentemente do nome, o fato é que a sua produção se encontra localizada no que tem-se denominado, genericamente, de estudos pós-coloniais, entendendo estes, segundo Ángel Octavio Álvarez Solis (2010) como "reflexões históricas, filosóficas e políticas de intelectuais que lograram articular de maneira critica as experiências coloniais de seus países (...) com os marcos categóricos ocidentais". Ainda para Solis (2010), a teoria critica decolonial articula-se, essencialmente, como um discurso contramoderno, no sentido de modernidade como um mito, ao tempo em que enuncia seu discurso a partir de um lugar de enunciação pos-colonial (entendendo o pós-colonial como o fim da relação juridico-político-formal, entre a metrópole e a colônia, do colonialismo histórico). Para este autor, é necessário fazer uma distinção entre situações, discursos e teorias poscoloniais. Situações pós-coloniais ocorrem quando há, num momento histórico, fatos que expressam ação de libertação frente a determinada situação de dominio colonial. Os discursos pós-coloniais ocorrem quando se produz pensamentos contra-hegemônicos e libertários diante de uma condição colonizadora. E as teorias pós-colonais se dão quando as experiências coloniais e os discursos anti-coloniais são pensados em conexão com categorias relacionadas com o colonialismo ocidental, no sentido de seu questionamento e de sua superação.

\footnotetext{
3 De acordo com Arturo Escobar, o Programa de pesquisa MC se constitui numa "maneira diferente de pensamento contrário às grandes narrativas modernistas - a cristianismo, o liberalismo e o marxismo localizando seu próprio questionamento nas bordas do sistema de pensamento e investigações para possibilitar modos de pensamentos não eurocêntricos" (ESCOBAR, 2003).
} 
O grupo tem fundamentado seu pensamento a partir de um exercício intergeracional e interdisciplinar. Nesse sentido, a sua produção cientifica advém de leituras, reflexões e diálogos cruzados nos campos da filosofia, da sociologia, da geografia, da semiologia, da história, do direito, da teologia, da economia, da literatura, enfim nos mais diversos eixos de produção de conhecimento, nos campos das ciências humanas, fundamentalmente vinculados à produção teórica de pensadores latino-americanos ${ }^{4}$ e seu lugar privilegiado de anunciação é a América Latina (ESCOBAR, 2003). Sua base e inspiração teóricas estão vinculadas à tradição do pensamento critico latino-americano consubstanciado historicamente na teologia da libertação, na teoria de dependência, na filosofia latino-americana, na pedagogia da libertação de Paulo Freire, mas também nos estudos pós-coloniais e subalternos, nos estudos culturais, no marxismo, nos estudos feministas, na filosofia afro-caribenha e estudos pós-estruturalistas (ESCOBAR, 2003, CASTRO-GOMES E GROSFOGUEL, 2007)

Suas criticas centram-se basicamente em relação à modernidade, ao capitalismo, ao eurocentrismo e à globalização, tendo como questionamento básico fatos históricos, sociais, econômicos, culturais - as epistemologias construídas e difundidas em torno - que se apresentam naturalizadas, pelas quais se tem buscado naturalizar suposta superioridade étnica de uns homens sobre outros, de territórios sobre outros, assim como de saberes sobre outros.

\section{Diálogos paradigmáticos}

Passemos agora a observar de que modo alguns dos autores mais presentes na nossa academia (hegemônico na disciplina em questão) pensam certas categorias caras às ciências sociais e humanas e, de outro lado, como

4 São muitos aqueles pensadores contemporâneos que têm produzido reflexões a respeito dos temas e categorias colocados pela Teoria Critica Decolonial. Podemos destacar os seguintes e suas respectivas principais contribuições teóricas: Filósofo argentino Enrique Dussel (filosofia da libertação, transmodernidade), Sociologo peruano Aníbal Quijano (colonialidade do poder), semiólogo argentino Walter Mignolo (geopolítica do conhecimento, diferença colonial), antropólogo colombiano Arturo Escobar (antropologias mundiais), a pedagoga norte-americana radicada no Equador Catherine Wash (interculturalidade), o portoriquenho Ramon Grosfoguel, o filosofo portoriquenho Nelson Madonaldo-Torres (colonialidade do ser), o filosofo colombiano Santiago Castro-Gomes (La hybris del punto cero), sociólogo venezuelano Edgardo Lander, o critico literário boliviano Javier Sanjinés, o venezuelano Fernando Caronil (já falecido), o norteamericano Imanuel Wallestein (sistema-mundo moderno), o geógrafo brasileiro Carlos Walter Porto-Gonçalves, entre outros. (ESCOBAR, 2003, CASTRO-GOMES E GROSFOGUEL, 2007) 
aqueles autores ausentes (os latino americanos) se colocam. Será um ensaio brevíssimo de dálogo de paradigmas.

A modernidade ${ }^{5}$ se constitui em um fenômeno essencialmente europeu, conforme pensam Habermas, Giddens, Taylor, Touraine, Liotard, Rorty, entre outros, assim como em Kant e Hegel e na Escola de Frankfurt (ESCOBAR, 2003). Por esta perspectiva, registra Arturo Escobar (2003), numa apertada síntese, a modernidade seria: i) sob o ponto de vista histórico, um fenômeno cultural surgido no século XVIII em torno da Reforma Protestante, do Iluminismo, da Revolução Francesa, consolidando-se com a Revolução Industrial; ii) sociologicamente, pelo advento do Estado-Nação, o desmembramento da vida social local para outros lugares e o distanciamento espaço-tempo (conforme Giddens); iii) culturalmente, pela crescente racionalização do mundo da vida junto com a universalização e individualização (Habermas). Ela se sustenta face ao dominio da razão, do individuo, do conhecimento especializado e da burocracia estatal, e iv) filosoficamente, de um lado, se caracteriza pela noção de homem com fundamento da razão desvinculada do natural e do sagrado. De outro lado, ela se apresenta, segundo Vattimo, “...pela ideia de história e seu corolário, progresso e superação. Vattimo enfatiza a lógica do desenvolvimento - a crença em um perpetuo melhoramento e superação - como crucial para a fundação filosófica da ordem moderna" (apud ESCOBAR, 2003).

No entanto, para a teoria critica decolonial, a partir da visão de Enrique Dussel, "o conceito emancipador da modernidade encobre um mito" (DUSSEL, 1994). Para o filósofo latino-americano, é necessário demolir o muro epistemológico que se estende desde os gregos até o presente, e que foi concebido sob o paradigma do mito eurocêntrico da modernidade. Tal mito surgiu com a chamada conquista pela Europa da América, desde o século XVI. Mas, todavia, segundo Dussel, foi com o século XVIII que a Europa passou a desenvolver uma visão de si mesma tendo a modernidade como um fenômeno exclusivamente seu

Sobre as fases históricas da modernidade, Walter Mignolo entende que, de 1500 a até hoje, ela se apresenta com três caras: a cara ibérica-católica, em que Portugual e Espanha dominam o cenário politico mundial - de 1500 a 1550, aproximadamente; a cara "coração da Europa" (Hegel) em que dominam Inglaterra, França e Alemanha - de 1550 até 1945, e a cara estadunidense liderada pelos Estados Unidos - de 1945 até hoje. (MIGNOLO, 2012) 
que se originou na idade média e ganhou corpo com os eventos históricos ocorridos no seu interior, tais como o Renascimento Italiano, o Iluminismo, a Reforma Protestante e a Revolução francesa.

De acordo com Dussel, foram Kant e Hegel os pensadores que deram sustentação filosófica importante para a construção do mito da modernidade (DUSSEL, 1994). Para Kant, o Iluminismo nada mais foi do que a saída da humanidade de um estado de "imaturidade culpável". Hegel, por sua vez, tem que o desenvolvimento, no sentido linear histórico, é um processo da humanidade que resulta na saída dessa "imaturidade culpável" e entrada no campo da iluminação da razão que só o Iluminismo possibilitou. Nesse sentido, segundo Hegel, "a história universal vai do Oriente ao Ocidente. Europa é absoltamente o fim da História Universal. Asia é o começo" (apud DUSSEL, 1994). Por essa posição, a América Latina e a África não fazem parte da História Mundial, enquanto a Asia se encontra naquele estágio de "imaturidade culpável". A humanidade tanto para Kant quanto para Hegel é a Europa e a Asia, esta ainda imatura. Segundo Hegel, a América, por não ter ainda terminado a sua formação, é a terra do futuro e, nessa condição, não interessa à filosofia que "não faz profecias". Para Hegel "Asia é a parte do mundo donde se verifica o começo enquanto tal [...] Porém, Europa é absolutamente o Centro e o Fim do mundo antigo e o Ocidente enquanto tal, a Asia é absoluto Oriente" (apud DUSSEL, 1994). Jürgen Habermas, outro filósofo europeu, já no século XX, defende que "Os acontecimentos chaves para a implantação do principio da subjetividade são a Reforma [protestante], o Iluminismo e a Revolução Francesa” (apud DUSSEL, 1994).7

Dussel contesta a posição dos filósofos que não vêm na América Latina como importante para a modernidade. Para ele, sem a América Latina a Europa não se constituiria como tal. No mesmo sentido: "A modernida-

- Mas a questão posta por Hegel não se limita, tão-somente, a uma leitura geopolitica a partir da Europa. Hegel também pensa a respeito dos povos da Africa, "os negros", para quem "é caracteristico o fato de sua consciência não ter chagado ainda à intuição de nenhuma objetividade, como por exemplo, Deus, a lei, na qual o homem está em relação com a sua vontade e tem a intuição de sua essencia [...] E um homem rude." (apud DUSSEL, 1994 ).

7 Na mesma trilha, Jose Manuel Romero Cuevas entende que: “... a teoria da modernidade e da modernização social de Habermas compartilha aspectos relevantes com o modelo de Hegel, a saber, a defesa de um padrão normativo de modernidade que coincide com o apresentado nos paises ocidentais desenvolvidos" (CUEVAS, 2007). 
de é uma narrativa européia que tem uma cara oculta e mais escura, que é a colonialidade" (MIGNOLO, 2012). Mais: o pensamento eurocêntrico, com o mito da modernidade, passou, de um lado, a definir a própria cultura como superior, mais desenvolvida e, de outro, as demais culturas como inferiores, bárbaras e, portanto, sujeitas a uma "imaturidade culpável”. Destarte, toda ação de dominação européia em relação aos demais povos se justifica como um ato de emancipação, de civilização do Outro dominado, pela sua condição de "imaturidade culpável", para se desenvolver e se modernizar e, só assim, chegar ao estagio de maturidade que só o europeu chegou. Eis o mito da modernidade centrado no eurocentrismo que produz a falácia desenvolvimentista, no dizer do filósofo latino-americano. E, assim, estamos até hoje condenado à "maturidade histórica".

No que toca ao eurocentrismo ${ }^{8}$, Nelson Maldonado-Torres (2008) observa, também nas posições de alguns filósofos europeus, como Martin Heidegger e Emmanuel Lévinas, a marca do esquecimento da colonialidade pela via da visão eurocêntrica. Para ele, o primeiro defendia, frente a uma crise da Europa, uma espécie de racismo epistêmico, quando louvava a superioridade da Alemanha em relação aos demais povos (era o seu germanocentrismo). A geopolítica de Heidegger é uma política baseada na relação íntima entre o povo, a sua língua e a sua terra. A geopolítica é, simultaneamente, uma política da terra e uma política de exclusão. Havia que proteger a Alemanha do "espírito francês do Iluminismo e da latinidade tanto da cultura gaulesa como da igreja católica" (Bambach, apud MALDONADO-TORRES, 2008). A geopolítica também se torna, para Heidegger, uma política de um racismo e de um imperialismo epistémicos.

Maldonado-Torres (2008) entende que Heidegger ao pensar assim estava baseado no que a Europa já fazia historicamente em relação ao resto do mundo, que era a subordinação epistêmica em dimensão imperial/colonial. Segundo este autor, Lévinas, por seu turno, embora conteste Heidegger, cai na mesma armadilha quando, a pretexto de defender (do racismo do filósofo alemão) o judaismo e os judeus, eleva a superioridade destes trazendo como cidades

\footnotetext{
8 Eurocentrismo, conforme sintese de Arturo Escobar (2003) é o "modelo de conhecimento que representa a experiência histórica local europea a qual tornou-se globalmente hegemônica desde o século XVII (Dussel, Quijano);” (ESCOBAR, 2003)
} 
modelos Atenas e Jerusalém que, para ele, se constituem nos verdadeiros alicerces do conhecimento para a humanidade. Nesse passo, a geopolitica de Lévinas não sai também dos muros europeus. Desde modo, ambos os filósofos, cada um a sua maneira, não viam fora da Europa qualquer possibilidade de existir "raça superior". Para Maldonado-Torres, visão semelhante poder ser encontrada ainda entre Antonio Negri, Slavoj Zizek, Jacques Derrida... (MALDONADO-TORRES, 2008).

Esse quadro de pensamento eurocêntrico acima exposto não vem do nada, tampouco segue para lugar nenhum. Na verdade, ele serve para justificar - ao mesmo tempo em que dele se alimenta - o padrão colonial de poder instituído pela Europa com as chamadas conquistas da América, a partir de 1492. Nesse sentido, para Aníbal Quijano (2000), a conquista da América possibilitou, de fato, a instituição de um novo padrão de poder mundial, denominado de matriz colonial de poder ou colonialidade, baseado em dois eixos principais de sustentação: Racismo e capitalismo. O primeiro se pauta pelo estabelecimento da diferença entre conquistado e conquistador fundamentado na ideia de raça, de modo a marcar aquele como inferior em relação a este. O segundo se expressa na articulação de toda forma de controle e exploração do trabalho e de seus recursos e produtos em torno do capital e do mercado mundial. Com a ideia de raça foram criadas identidades sociais novas: indios, negros, mestiços, assim como identidades postas a partir da localização geográfica, tais como espanhol, portugues e europeu, identidades estas que serviam (e ainda servem) para configurar relações de dominação. Com o tempo, os negros e indios passaram a ser identificados como os dominados e colonizados, e os europeus, os brancos, como dominadores e colonizadores. Tem-se assim a raça dominante e a raça dominada. E, com isso, "uma nova tecnologia de dominação/exploração, neste caso raça/trabalho, articulou-se de maneira que aparecesse como naturalmente associadas, o que, até o momento, tem sido excepcionalmente bem sucedido" (QUIJANO, 2000).

A colonialidade se constitui, conforme Quijano (2000), na dominação colonial que subsiste ao fim do instituto jurídico-político-formal da 
colônia (e do colonialismo) e que impregna cada uma das áreas da existência social constituindo-se como o mais profundo e eficaz formato de dominação social, material e intersubjetiva. É o esquadro mais universal de dominação política dentro do atual padrão de poder, e que dar conta da dependência histórico-estrutural assim como das características específicas do aspecto societal na América Latina (MARTINEZ-ANDRADE, 2008). A colonialidade do poder se fortaleceu com a colonialidade do saber, o que ocorreu graças à ideologia do progresso e as ciências sociais (WALLERSTEIN, 2007) que com o seu positivismo e dogmatismo prestou-se como instrumento a serviço do poder colonial.

Descolonialidade ou descolonização seriam processos sociais de resistência à matriz colonial de poder por meio de atos de desprendimento com vistas à formulação de um pensamento de fronteira (MIGNOLO, 2010). São estratégias epistemológicas que levam a pensar de que modo é possível mover-se na exterioridade do pensamento eurocêntrico e de suas categorias. Nesse sentido, Walter Mignolo (2010) tem desenvolvido o que chama de pensamento de fronteira - que se constitui na possibilidade de se pensar externamente ao padrão epistemológico dominante - pelo qual é possível enfrentá-lo, não importa se de esquerda ou de direita, desde que a partir de forças epistêmicas localizadas no que a modernidade converteu, ao longo da história, em formas subalternas de conhecimento - como são tidos os conhecimentos tradicionais, folclóricos, religiosos, emocionais, etc - no sentido de romper com o eurocentrismo como a única perspectiva epistemológica visto haver, de fato, diferentes espaços aonde se produz pensamento (ESCOBAR, 2003).

Portanto, a noção de modernidade com a qual temos epistemológicamente convivido - especialmente por conta dos processos de difusão/ inculcação acadêmicas - não se presta a fazer com que possamos compreender, a partir do lugar de enunciação de nossas realidades geo-históricas, os tipos de sociedade, de política e de natureza que nos identifica, nos interessa e nos satisfaz como sujeitos latino-americanos. Com ela, continuamos a pensar pela cabeça alheia. Imaturos, sempre?

Para Santiago Castro-Gomes (2007), para sair dessa condi- 
ção eurocêntrica, é preciso que se descolonize a universidade, o que significa torná-la um campo de prática transdisciplinar e também de possibilidades para o diálogo de saberes de modo que "diferentes formas culturais de conhecimentos possam conviver no mesmo espaço universitário". A fim de deixar claro referida ideia de descolonização com a qual concordamos plenamente, Castro-Gomes esclarece que tal defesa:

no conlleva una cruzada contra Occidente en nombre de algún tipo de autoctonismo latinoamericanista, de culturalismos etnocéntricos y de nacionalismos populistas, como suelen creer algunos. Tampoco se trata de ir en contra de la ciencia moderna y de promover un nuevo tipo de oscurantismo epistémico. Cuando decimos que es necesario ir "más allá" de las categorías de análisis y de las disciplinas modernas, no es porque haya que negarlas, ni porque éstas tengan que ser "rebasadas" por algo "mejor". Hablamos, más bien, de una ampliación del campo de visibilidad abierto por la ciencia occidental moderna, dado que ésta fue incapaz de abrirse a dominios prohibidos, como las emociones, la intimidad, el sentido común, los conocimientos ancestrales y la corporalidad. No es, entonces, la disyunción sino la conjunción epistémica lo que estamos pregonando. Un pensamiento integrativo en el que la ciencia occidental pueda "enlazarse" con otras formas de producción de conocimientos, con la esperanza de que la ciencia y la educación dejen de ser aliados del capitalismo posfordista (CASTRO-GOMES, 2007).

\section{CRitical DECOlONial THEORY: AN EPISTEMOlOgiCAL VOID IN BRAZILIAN ACADEMIA}

RESUMO: This article briefly introduces Decolonial theory, its position on the idea of modernity, and the epistemologies that originated from it, especially through Social Sciences and Humanities, in Latin America. This work attempts at drawing attention to an "epistemological void" in Brazilian academia, namely the absence of a proper dissemination of the so-called post-colonial studies, which would have opened the possibility to access a different knowledge model, against the quasi-total domination of social theories coming from Europe and the US. Therefore, the article brings to debate an empiric case-study of this void in Brazilian academia: the syllabus of the module "Theory of Society, Politics and Nature" - from the Interdisciplinary Postgraduate curse 
João José Veras de Souza

in Humanities of the Federal University of Santa Catarina (UFSC).

PALAVRAS-CHAVE: Teoria critica decolonial. Modernidade. Colonialidade. Academia brasileira.

\section{Rererências}

CASTRO-GOMES, S.; GROSFOGUEL, R. Prólogo: Giro decolonial, teoria crítica y pensamineto heteráquico. In: El giro decolonial. Reflexiones para una diversidad epistémica más allá del capitalismo global. Santiago Castro-Gómez y Ramón Grosfoguel (eds.),Bogotá: Iesco-Pensar-Siglo del Hombre Editores. 2007.

CASTRO-GOMES, S. Decolonizar la universidad. La hybris del punto cero y el dialogo de saberes In: El giro decolonial. Reflexiones para una diversidad epistémica más allá del capitalismo global. Santiago Castro-Gómez y Ramón Grosfoguel (eds.), Bogotá: Iesco -Pensar-Siglo del Hombre Editores. 2007.

CONNELL, R. A iminente revolução na teoria social. Trad. João Maia. Revista Brasileira de Ciências Sociais, Vol. 27 nº 80, 2012.

CUEVAS, J. M. R. Progresso, Retorno de lo igual y otras paradojas de la modernidade - Por una discusión com Jurgens Habermas. In De la Teoria Critica a una plural critica plural de la modernidade. Oliver Kozlarek, coordinador. Buenos Aires. Biblos. 2007.

DUSSEL, E. 1492. El encubrimiento del Otro - Hacia el origen del "mito de la Modernidade. Conferencias de Frankfurt, Octubre 1991. Plural editores. Centro de Información para el Desarrollo, CID, La Paz, 1994.

DUSSEL, E. Eurocentrismo y Modernidade (Introducción a la lecturas de Frankfurt) In Capitalismo y Geopolitica del Conocimiento - O eurocentrismo y la filosofia de la liberación en el debate intelectual contemporaneo. Walter Mignolo, compilador. Ediciones del Signo/Duke University. Buenos Aires. 2001.

EDGARDO, L. (ed.). La Colonialidad del saber: Eurocentrismo y Ciencias Sociales. Perspectivas Latinoamericanas. Caracas: Clacso, 2000.

ESCOBAR, A. Mundos y conhecimientos de outro modo - O programa de investigacion de modernidade/colonialidad latinoamericano. Colômbia: Revista Tabula Rasa. $\mathrm{n}^{\circ}$ $1,2003$. 
João José Veras de Souza

MALDONADO-TORRES, N. A topologia do ser e a geopolitica do conhecimento. Modernidade, império e colonialidade. In Revista Critica de Ciências Sociais, $\mathrm{n}^{\circ}$ 80, março de 2008. http://goo.gl/jj9pZP. Acesso em 05.07.2012.

MARTINEZ-ANDRADE, L. La reconfiguración de la colonialidad Del poder y nla construcions del Estado-nación em America Latina. Amérique Latine Histoire et Mémoire. Les Cabiers ALHIM, 15 | 2008, [En línea], Puesto en línea el 29 jun 2009. URL: http:// goo.gl/FXwGYI. Acesso em 10/12/2010.

MIGNOLO, W. La ideia de américa latina. La herida colonial y la opción decolonial. Gedisa Editorial. Barcelona. 2005.

MIGNOLO, W. Desobediência Epistêmica - Retórica de la modernidad, lógica de la colonialid e gramática de la descolonialid. Ediciones del Signo. Buenos Aires: 2010.

MIGNOLO, W. La colonialidad: la cara oculta de la modernidad. Conforme http://goo. gl/NVxp5x. Acesso em 10.03.2012.

QUIJANO, A. Os Fantasmas da América Latina. In Oito Visões da América Latina. Adauto Novaes (org.). São Paulo: Editora Senac. 2006.

SANTOS, M. O Pais distorcido. Jornal A Folha de São Paulo, edição de 02/05/1999.

SOLÍS, Ángel Octavio Álvarez. La persistência de los márgenes. Reflexiones epistemológicas em trono a la obra de Walter Mignolo. México: Araucaria - Revista Iberoamericana de Filosofia, política e Humanidades. Ano 12. No 21. 2010.

WALLERSTEIN, I. Abrir las ciências sociales. Informe de la Comisión Gulberian para la reestructuración de lãs ciências sociales. Espanha: Siglo XXI editores de Espanha S.A. 2007.

Data de recebimento: 10/11/2014

Data de aceite: 14/12/2014 